\title{
Genetic diversity and population structure of Iranian isolates of Fusarium oxysporum f. sp. ciceris, the causal agent of chickpea wilt, using ISSR and DAMD-PCR markers
}

\author{
Mohammad Kazem Montakhabi ${ }^{1 *}$, Gholam Hosein Shahidi Bonjar ${ }^{1}$, Reza Talebi ${ }^{2}$ \\ ${ }^{1}$ Department of Plant Pathology, Shahid Bahonar University Kerman, Kerman, Iran \\ ${ }^{2}$ Department of Agricultural Biotechnology, Sanandaj Branch, Islamic Azad University, Sanandaj, Iran \\ ${ }^{\star}$ Corresponding author, E-mail: mkmontakhabi@gmail.com
}

\begin{abstract}
Fusarium oxysporum f. sp. ciceris (FOC), is one of the most important soil-borne diseases of chickpea in the world. In order to study the genetic diversity of Iranian FOC isolates, sixty five isolates of the pathogen were isolated from wilted chickpea plants from different chickpea growing areas of West of Iran. Phylogenetic analysis using ISSR and DAMD-PCR markers grouped FOC isolates into six and five distinct groups, respectively. Both ISSR and DAMD-PCR markers showed a high level of polymorphism and were found to be effective in determining genetic diversity in FOC isolates. The genetic structure of 65 FOC isolates showed the highest peak at $K=5$ indicating the that the collected FOC isolates should be divided into five populations. The results of FOC grouping by ISSR and DAMDPCR markers showed relatively low correlation with geographic origins. Overall, our results showed a high genetic diversity level in Iranian FOC isolates, which might be mediated by gene mutation or chromosomal segment loss and may suggest a longer evolutionary period for FOC isolates from the chickpea growing area in the west of Iran. The results of the presented study will be useful to chickpea breeders for effective selection of durable resistance sources.
\end{abstract}

Key words: chickpea, DAMD-PCR, Fusarium oxysporum f. sp. ciceris, genetic diversity, ISSR.

Abbreviations: DAMD, direct amplified of minisatellite DNA; FOC, Fusarium oxysporum f. sp. ciceris; ISSR, inter-simple sequence repeat.

\section{Introduction}

Chickpea (Cicer arietinum L.) is one of the most important legume crops as a cheap protein source in many countries in Asia and Africa (Jannatabadi et al. 2014; Hajibarat et al. 2015). The countries located in the Middle-East such as India, Turkey, Pakistan and Iran, are the major chickpea producers in Asia (Mohammadi, Talebi 2015). In Iran, chickpea production is low, which may be attributed to several abiotic and biotic stresses such as drought, cold and fungal diseases (Patil et al. 2005; Jendoubi et al. 2017). Fusarium wilt, caused by Fusarium oxysporum f. sp. ciceris (FOC), is one of the major fungal diseases in chickpea production worldwide (Jalali, Chand 1992; Cachinero et al. 2002). This disease has been reported in most chickpea production areas in the world, however, the chickpea producing countries that are more threatened by this disease are Iran, India, Pakistan, Spain and Tunisia (Chand, Khirbad 2009). Depending upon the environmental conditions, this disease can be devastating to chickpea yield 10 to $15 \%$ each year in regular conditions, and can reach up to $100 \%$ in some improved chickpea cultivars in unfavorable agroclimatic conditions (Mohamed et al.2015).

FOC symptoms can develop at any stage of plant growth with higher incidence during the flowering and pod filling stages (Jiménez-Díaz et al. 2015; Jendoubi et al. 2017). This pathogen is soil and seed-born and in the absence of the chickpea host, it can survive on plant debris in soil for more than six years (Haware et al. 1978). Based on disease symptoms, pathotypes can be divided into two groups as distinct yellow or wilting syndromes (JiménezGasco et al. 2004; Jiménez-Díaz et al. 2015). The yellowing pathotype causes foliar yellowing, vascular discoloration and late plant death, while the wilting pathotype induces very fast chlorosis, vascular discoloration and early plant death (Jiménez-Fernández et al. 2013; Jendoubi et al. 2017). Based on disease severity and virulence of FOC isolated on a set of chickpea differential lines, eight distinct races of FOC (races $0,1 \mathrm{~A}, 1 \mathrm{~B} / \mathrm{C}, 2,3,4,5$ and 6 ) have been identified (Jiménez-Gasco et al. 2004; Sharma, Muehlbauer 2007).

Considering the nature and survival ability of FOC fungi, management of wilt disease through fungicide and agronomical practices are difficult and are not environment friendly methods. Thus, the most effective methods for management of chickpea wilt are the use of resistance sources in breeding programs (Bakhsh et al. 2007). However, evolution of new races poses a serious threat to deployment of wilt resistance in chickpea. Analysis of plant 
pathogen populations is useful for improving cultivars that are resistant to the pathogen populations (Aghamiri et al. 2015). This information helps breeders to develop new strategies to achieve durable disease resistance (Talebi et al. 2010).

In the recent years, molecular genetic markers have been widely used for assessing the genetic variation and origin identification in many species (Hajibarat et al. 2015). FOC, the causal agent of chickpea wilt has a high diversity in nature and assessment of variability in the population of FOC has been made by several workers at morphological, pathogenic and molecular levels. Genetic diversity in $F$. oxysporium causing diseases as well as in FOC isolates has been explored using different types of molecular markers such as RAPD (Sivaramakrishnan et al. 2002; Mohamed et al. 2015); SCAR (Jimenez-Gasco, Jimenez-Diaz 2003); SSR (Mohamed et al. 2015); AFLP (Jimenez-Gasco et al. 2001; Madhuri, Mane 2012); ITS-RFLP (Gurjar et al. 2009); and BOX-and rep-PCR (Muiru et al. 2010; Kashyap et al. 2016). The aim of this study was to investigate the genetic variability and population structure analysis of 65 FOC isolates originated from north-west Iran (Kurdistan and Kermanshah provinces) using inter-simple sequence repeat (ISSR) and direct amplified of minisatellite DNA (DAMD) molecular markers.

\section{Materials and methods}

\section{Isolation of Fusarium oxysporum $f$. sp. ciceri and DNA extraction}

Sixty five isolates of Fusarium oxysporum f. sp. ciceri were collected from eight chickpea cultivation zones from two provinces (Kordestan and Kermanshah) located in northwest Iran (Table 1). All FOC isolated were obtained from the infected stems of chickpea plants showing vascular discoloration symptoms. Infected plant parts were washed and cut into small pieces. All samples surface disinfected by $1 \%$ hypochlorite sodium for $2 \mathrm{~min}$ and then washed twice with sterilized distilled water and plated on potato dextrose agar. Plates were incubated at room temperature $\left(25^{\circ} \mathrm{C}\right.$ ) for six days with a $12 \mathrm{~h}$ photoperiod (Mohamed et al. 2015). FOC cultures were purified from single-spore culture and incubated on potato dextrose broth (potato 200 $\mathrm{g}$, dextrose $20 \mathrm{~g}$, agar $18 \mathrm{~g}$ and $1 \mathrm{~L}$ water) for eight days. Fungal mycelium was harvested from cultures and used for DNA extraction using CTAB method as described by Kumar et al. (2013). DNA concentrations were estimated by both spectrophotometry (260/280) and gel electrophoresis $(0.8 \%$ agarose gel $)$ and used for PCR analysis in final concentration of $30 \mathrm{ng} \mu \mathrm{L}^{-1}$.

\section{Pathogenicity test}

Pathogenicity tests of FOC isolates were carried out in controlled greenhouse conditions using a root dip inoculation method (Pande et al. 2007). Isolated FOC were grown in potato dextrose broth media and incubated for seven days at room temperature. The inoculum suspensions were filtered and adjusted to $5 \times 10^{6}$ conidia $\mathrm{mL}^{-1}$ concentration. Seedlings of the wilt-susceptible chickpea $\mathrm{cv}$. Bivanij were grown in perlite for 14 days. Seedlings were carefully uprooted and roots of seedlings were dipped in inoculum of each isolate for 2 to $3 \mathrm{~min}$. Root-inoculated plants were transferred to sterile soil plus sand and pots kept in controlled greenhouse at $24{ }^{\circ} \mathrm{C}$. Five pots with three plants in each pot were used for each isolate. Disease symptoms were observed 20 to 25 days after inoculation. Disease severity of each isolates was evaluated at 28 days after inoculation based on percentage of plants death for each isolates and graded as avirulent ( $0 \%$ wilt), less virulent ( $1-20 \%$ wilt), moderately virulent $(21-50 \%$ wilt) and highly virulent (> 51\% wilt) (Kashyap et al. 2016).

Table 1. Description of the isolates of Fusarium oxysporum f. sp. ciceris, collection site, morphological features and pathogenicity test on cv. Bivanij

\begin{tabular}{llcccc} 
No. & Isolate & Origin (province/collection site) & Colony color & $\begin{array}{c}\text { Clamydospore } \\
\text { position }\end{array}$ & $\begin{array}{c}\text { Disease severity (\% of } \\
\text { wilt incidence) }\end{array}$ \\
\hline 1 & Foc1 & Kermanshah/Sarab-Nilofar & Yellowish & Intercalary & 35.1 \\
2 & Foc2 & Kermanshah/Sarab-Nilofar & White & Intercalary & 91.2 \\
3 & Foc3 & Kermanshah/Sarab-Nilofar & Yellowish & Intercalary & 92 \\
4 & Foc4 & Kermanshah/Sarab-Nilofar & Yellowish & Both & 39.8 \\
5 & Foc5 & Kermanshah/Sarab-Nilofar & Pinkish white & Intercalary & 42.8 \\
6 & Foc6 & Kermanshah/Sarab-Nilofar & White & Absent & 44.6 \\
\hline 7 & Foc7 & Kermanshah/Sarab-Nilofar & Pinkish white & Intercalary & 38.5 \\
8 & Foc8 & Kurdistan/Kamyaran & Yellowish & Intercalary & 34.2 \\
\hline 9 & Foc9 & Kurdistan/Kamyaran & Yellowish & Intercalary & 12.7 \\
10 & Foc10 & Kurdistan/Kamyaran & Yellowish & Both & 26.4 \\
11 & Foc11 & Kurdistan/Kamyaran & Pinkish white & Absent & 29.4 \\
12 & Foc12 & Kurdistan/Kamyaran & White & Intercalary & 21.7 \\
13 & Foc13 & Kurdistan/Kamyaran & Pinkish white & Intercalary & 24.2 \\
continued & & & &
\end{tabular}


Table 1. continued

\begin{tabular}{|c|c|c|c|c|c|}
\hline No. & Isolate & Origin (province/collection site) & Colony color & $\begin{array}{l}\text { Clamydospore } \\
\text { position }\end{array}$ & $\begin{array}{c}\text { Disease severity (\% of } \\
\text { wilt incidence) }\end{array}$ \\
\hline 14 & Foc14 & Kurdistan/Kamyaran & Yellowish & Intercalary & 16.7 \\
\hline 15 & Foc15 & Kurdistan/Kamyaran & Yellowish & Intercalary & 27.2 \\
\hline 16 & Foc16 & Kurdistan/Kamyaran & White & Absent & 29.5 \\
\hline 17 & Foc17 & Kermanshah/Sararood & Yellowish & Intercalary & 44.7 \\
\hline 18 & Foc18 & Kermanshah/Sararood & Yellowish & Intercalary & 91.7 \\
\hline 19 & Foc19 & Kermanshah/Sararood & Pinkish white & Intercalary & 42.8 \\
\hline 20 & Foc20 & Kermanshah/Sararood & Pinkish white & Intercalary & 90.7 \\
\hline 21 & Foc21 & Kermanshah/Sararood & Yellowish & Both & 46.5 \\
\hline 22 & Foc 22 & Kermanshah/Sararood & White & Absent & 44.5 \\
\hline 23 & Foc23 & Kermanshah/Sararood & Pinkish white & Intercalary & 42.8 \\
\hline 24 & Foc24 & Kermanshah/Sararood & Yellowish & Intercalary & 46.1 \\
\hline 25 & Foc25 & Kermanshah/Sararood & Pinkish white & Intercalary & 45.9 \\
\hline 26 & Foc26 & Kermanshah/Sararood & White & Intercalary & 42.8 \\
\hline 27 & Foc27 & Kermanshah/Dorood Faraman & Yellowish & Absent & 49.7 \\
\hline 28 & Foc28 & Kermanshah/Dorood Faraman & Yellowish & Intercalary & 46.5 \\
\hline 29 & Foc29 & Kermanshah/Dorood Faraman & White & Intercalary & 49.6 \\
\hline 30 & Foc30 & Kermanshah/Dorood Faraman & Yellowish & Both & 48.2 \\
\hline 31 & Foc31 & Kermanshah/Dorood Faraman & White & Intercalary & 49.4 \\
\hline 32 & Foc32 & Kermanshah/Dorood Faraman & Pinkish white & Intercalary & 47.5 \\
\hline 33 & Foc33 & Kermanshah/Dorood Faraman & Pinkish white & Intercalary & 91.5 \\
\hline 34 & Foc34 & Kurdistan/Kani-Charmoo & Yellowish & Intercalary & 18.2 \\
\hline 35 & Foc35 & Kurdistan/Kani-Charmoo & White & Intercalary & 25.8 \\
\hline 36 & Foc36 & Kurdistan/Kani-Charmoo & Pinkish white & Intercalary & 19.1 \\
\hline 37 & Foc37 & Kurdistan/Kani-Charmoo & Yellowish & Both & 29.6 \\
\hline 38 & Foc38 & Kurdistan/Kani-Charmoo & Yellowish & Intercalary & 31.5 \\
\hline 39 & Foc39 & Kurdistan/Kani-Charmoo & Pinkish white & Absent & 30.8 \\
\hline 40 & Foc40 & Kurdistan/Kani-Charmoo & Pinkish white & Intercalary & 34.2 \\
\hline 41 & Foc41 & Kurdistan/Kani-Charmoo & Yellowish & Absent & 31.2 \\
\hline 42 & Foc42 & Kurdistan/Kani-Charmoo & Yellowish & Intercalary & 28.8 \\
\hline 43 & Foc43 & Kurdistan/Kani-Charmoo & Yellowish & Both & 29.6 \\
\hline 44 & Foc44 & Kurdistan/Kani-Charmoo & Yellowish & Absent & 29.1 \\
\hline 45 & Foc45 & Kurdistan/Kani-Charmoo & White & Intercalary & 30.4 \\
\hline 46 & Foc46 & Kermanshah/Gomateh & Pinkish white & Intercalary & 44.2 \\
\hline 47 & Foc47 & Kermanshah/Gomateh & yellowish & Intercalary & 46.2 \\
\hline 48 & Foc48 & Kermanshah/Gomateh & Pinkish white & Intercalary & 39.1 \\
\hline 49 & Foc49 & Kermanshah/Gomateh & Yellowish & Absent & 35.8 \\
\hline 50 & Foc50 & Kermanshah/Gomateh & white & Intercalary & 45.2 \\
\hline 51 & Foc51 & Kermanshah/Gomateh & Yellowish & Intercalary & 44 \\
\hline 52 & Foc52 & Kermanshah/Gomateh & Yellowish & Intercalary & 46 \\
\hline 53 & Foc53 & Kermanshah/Korani & Pinkish white & Intercalary & 37.1 \\
\hline 54 & Foc54 & Kermanshah/Korani & Yellowish & Both & 35.5 \\
\hline 55 & Foc55 & Kermanshah/Korani & White & Absent & 33.4 \\
\hline 56 & Foc56 & Kermanshah/Korani & Yellowish & Intercalary & 39.1 \\
\hline 57 & Foc57 & Kermanshah/Korani & Yellowish & Intercalary & 32 \\
\hline 58 & Foc58 & Kermanshah/Korani & Pinkish white & Absent & 42 \\
\hline 59 & Foc59 & Kermanshah/Korani & White & Intercalary & 41 \\
\hline 60 & Foc60 & Kermanshah/Korani & Yellowish & Absent & 42.1 \\
\hline 61 & Foc61 & Kermanshah/Mahidasht & Pinkish white & Intercalary & 46.8 \\
\hline 62 & Foc62 & Kermanshah/Mahidasht & Yellowish & Intercalary & 49.1 \\
\hline 63 & Foc63 & Kermanshah/Mahidasht & white & Absent & 45.6 \\
\hline 64 & Foc64 & Kermanshah/Mahidasht & Pinkish white & Intercalary & 47.6 \\
\hline 65 & Foc65 & Kermanshah/Mahidasht & Pinkish white & Both & 43.8 \\
\hline
\end{tabular}


Table 2. Description of ISSR and DAMD-PCR markers used for genetic diversity analysis in Fusarium oxysporum $\mathrm{f}$. sp. ciceris isolates

\begin{tabular}{|c|c|c|c|c|}
\hline Type & Marker & Sequence $(5 /$ to $3 /)$ & GC (\%) & $\operatorname{Tm}\left({ }^{\circ} \mathrm{C}\right)$ \\
\hline \multirow[t]{10}{*}{ ISSR } & UBC807 & AGAGAGAGAGAGAGAGT & 47 & 50 \\
\hline & UBC812 & GAGAGAGAGAGAGAGAA & 47 & 45 \\
\hline & UBC815 & СТстстстСтстстстG & 52 & 44 \\
\hline & UBC816 & CACACACACACACACAT & 47 & 48 \\
\hline & UBC818 & CACACACACACACACAG & 52 & 52 \\
\hline & UBC828 & TGTGTGTGTGTGTGTGA & 47 & 52 \\
\hline & UBC864 & ATGATGATGATGATGATG & 33 & 52 \\
\hline & UBC868 & GAAGAAGAAGAAGAAGAA & 33 & 48 \\
\hline & UBC878 & GGATGGATGGATGGAT & 50 & 54 \\
\hline & UBC880 & GGAGA GAGAGGAGA & 60 & 50 \\
\hline \multirow[t]{10}{*}{ DAMD-PCR } & URP1F & ATCCAAGGTCCGAGACAACC & 55 & 50 \\
\hline & URP2F & GTGTGCGATCAGTTGCTGGG & 60 & 50 \\
\hline & URP6R & GGCAAGCTGGTGGGAGGTAC & 65 & 50 \\
\hline & URP4R & AGGACTCGATAACAGGCTCC & 55 & 50 \\
\hline & URP9F & ATGTGTGCGATCAGTTGCTG & 50 & 50 \\
\hline & URP13R & TACATCGCAAGTGACACAGG & 50 & 50 \\
\hline & URP17R & AATGTGGGCAAGCTGGTGGT & 55 & 50 \\
\hline & URP25F & GATGTGTTCTTGGAGCCTGT & 50 & 50 \\
\hline & URP30F & GGACAAGAAGAGGATGTGGA & 50 & 50 \\
\hline & URP38F & AAGAGGCATTCTACCACCAC & 50 & 50 \\
\hline
\end{tabular}

\section{Genetic diversity analysis by ISSR and DAMD-PCR molecular markers}

For ISSR analysis, a set of 10 primers (UBC set, University of British Columbia, Canada) were used to assessing genetic diversity among FOC isolates (Table 2). Ten DAMD-PCR markers (originally derived from the repeat elements of weed rice) (Kang et al. 2002) were used in this study (Table 2). PCR amplification was performed in $20 \mu \mathrm{L}$ reaction containing $1 \times$ PCR buffer, $30 \mathrm{ng}$ sample DNA, $2.5 \mu \mathrm{M}$ primer, $200 \mu \mathrm{M}$ of each dNTP, $1.5-2.5 \mathrm{mM}$ $\mathrm{MgCl} 2$ and 1.5 units of Taq DNA polymerase (Cinnagene, Iran). All amplification were carried out in a Eppendorf thermocyclers as follows: $94{ }^{\circ} \mathrm{C}$ for $3 \mathrm{~min}$, followed by 35 cycles of denaturation at $93{ }^{\circ} \mathrm{C}$ for $45 \mathrm{~s}$, annealing at optimum Ta for $45 \mathrm{~s}$, and extension at $72^{\circ} \mathrm{C}$ for $90 \mathrm{~s}$. A final extension cycle at $72{ }^{\circ} \mathrm{C}$ for $10 \mathrm{~min}$ followed. PCR products were separated on $1.4 \%$ agarose gels, stained with ethidium bromide and scored for the presence or absence of bands.

\section{Data analysis}

PCR products of ISSR and URP (Universal Rice Primer) primers were scored visually. For each marker, bands were scored visually for the presence (1) and absence (0) of bands for all the 65 FOC isolates. Cluster analysis using un-weighted pair-group method with arithmetic averages (UPGMA) using the similarity matrixes were performed by DARwin program package (Perrier and JacquemoudCollet, 2006). For both ISSR and URP-based clusters the fit of dendrograms obtained were checked by bootstrapping using 1000 replications, and only bootstrap values higher than $50 \%$ are presented. Polymorphic information content
(PIC) values were calculated for each ISSR and URP primers according to the formula: PIC $=1-\Sigma(\mathrm{Pij})^{2}$, where $\mathrm{Pij}$ is the frequency of the ith pattern revealed by the jth primer summed across all patterns revealed by the primers. Marker index (MI) was obtained by multiplying the average PIC with the Effective multiplex ratio. Effective multiplex ratio (EMR) is the product of the number of polymorphic loci per primer (n) and the fraction of polymorphic fragments (Perrier et al. 2003). For the analysis of population structure, a Bayesian model-based analysis was performed using STRUCTURE 2.1 software (Pritchard et al. 2000). A Monte Carlo Markov chain method was used to estimate allele frequencies in each of the $\mathrm{K}$ populations and the degree of admixture for each individual plant. The number of clusters was inferred using 10 independent simultaneous runs with 10000 replications using the admixture model and correlated allele frequencies with the $\mathrm{K}$ value ranging from 1 to 10 .

\section{Results}

\section{Pathogenicity test of the FOC isolates}

Disease severity and vascular discoloration caused by FOC isolates on cv. Bivanij showed variability between isolates. In general, among all the isolates, FOC isolates collected from the Kermanshah province showed more aggressiveness and caused the maximum wilt incidence $(>80 \%)$ on the susceptible cv. Bivanij. Isolates Foc2, Foc3, Foc18, Foc20 and Foc33 showed maximum wilt incidence ( 92\%) and isolates from Kurdistan showed less aggressiveness. Isolates Foc9, Foc14, Foc34, Foc36 showed least wilt incidence 
(>20\%) in comparison to other FOC isolates. The other isolates differed in their virulence behavior and showed moderately virulent ( $21-50 \%$ wilt damage).

\section{$R$ and $D A M D-P C R$ diversity pattern}

ISSR and DAMD-PCR analysis revealed clear and scorable bands per primer. Ten ISSR markers amplified 155 bands, of which 87 bands (56.1\%) were polymorphic (Table 3 ) with an average of 8.7 polymorphic bands per primer. The maximum and minimum number of polymorphic bands were obtained using UBC816 (12 bands) and UBC880 (6 bands), respectively. The PIC values for the 10 ISSR primers ranged from 0.22 (UBC880) to 0.43 (UBC816) with an average of 0.36 per primer. The marker index (MI) of the primers ranged from 0.99 (UBC880) to 4.11 (UBC816) (Table 3). Ten DAMD-PCR markers produced 88 bands across 65 FOC isolates, of which 55 were polymorphic (62.5\%) with an average of 5.5 polymorphic bands per primer (Table 3). Most of the DAMD-PCR markers generated six polymorphic bands and the least number of polymorphic bands was observed for URP9F (4 bands). The PIC values for the DMAD-PCR primers ranged from 0.19 (URP9F) to 0.32 (URP2F) with an average of 0.25 per primer. The marker index (MI) of the primers ranged from 0.69 (URP9F) to 2.59 (URP2F) (Table 3). Un-weighted pairgroup (UPGMA) clustering using ISSR and DAMD-PCR molecular dataset grouped the FOC isolates in six and five distinct groups, respectively (Fig. 1 and Fig. 2). Similarity between genotype clustering in ISSR and DAMD analyses based on the Mantel coefficient test showed relatively high, but non-significant correlation $(r=0.41)$.

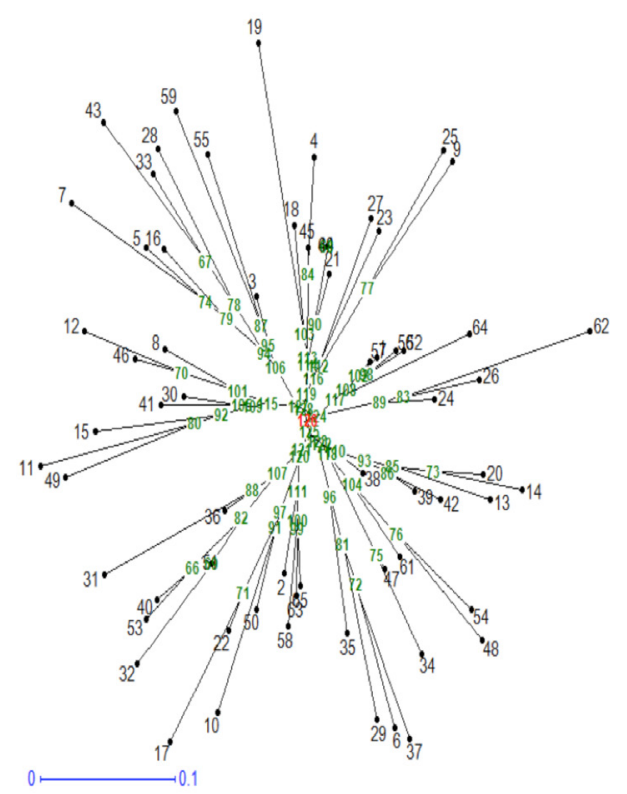

Fig. 1. Cluster analysis of 65 of Fusarium oxysporum f. sp. ciceris isolates obtained by ISSR markers.
Table 3. Description of the polymorphism, PIC and marker index (MI) values of ISSR and DAMD-PCR markers used in the genetic diversity analysis of FOC isolates

\begin{tabular}{lcccc} 
Primer & $\begin{array}{c}\text { Number } \\
\text { of } \\
\text { amplified } \\
\text { bands }\end{array}$ & $\begin{array}{c}\text { Number of } \\
\text { polymorphic } \\
\text { bands }\end{array}$ & PIC & MI \\
\hline ISSR & 14 & 10 & 0.41 & 3.87 \\
\hline UBC807 & 12 & 9 & 0.36 & 2.39 \\
\hline UBC812 & 16 & 11 & 0.42 & 3.98 \\
\hline UBC815 & 16 & 10 & 0.40 & 3.21 \\
\hline UBC816 & 18 & 12 & 0.43 & 4.11 \\
\hline UBC818 & 14 & 8 & 0.34 & 2.19 \\
\hline UBC828 & 19 & 12 & 0.39 & 2.77 \\
\hline UBC864 & 14 & 10 & 0.38 & 3.01 \\
\hline UBC868 & 16 & 10 & 0.35 & 2.67 \\
\hline UBC878 & 17 & 11 & 0.34 & 2.46 \\
\hline UBC880 & 13 & 6 & 0.22 & 0.99 \\
\hline DAMD-PCR & 10 & 7 & 0.35 & 2.78 \\
\hline URP1F & 9 & 6 & 0.31 & 2.54 \\
\hline URP2F & 12 & 6 & 0.32 & 2.59 \\
\hline URP6R & 9 & 5 & 0.26 & 1.28 \\
\hline URP4R & 10 & 6 & 0.29 & 1.41 \\
\hline URP9F & 9 & 4 & 0.19 & 0.69 \\
\hline URP13R & 10 & 5 & 0.24 & 0.89 \\
\hline URP17R & 11 & 6 & 0.23 & 0.82 \\
\hline URP25F & 9 & 6 & 0.25 & 0.91 \\
\hline URP30F & 9 & 5 & 0.24 & 0.84 \\
\hline URP38F & 10 & 6 & 0.21 & 0.77 \\
\hline
\end{tabular}

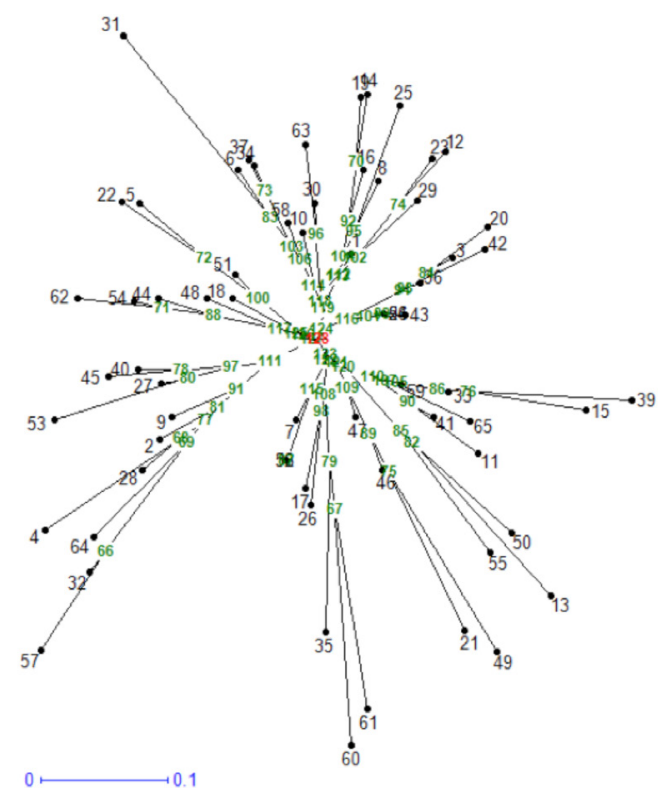

Fig. 2. Cluster analysis of 65 of Fusarium oxysporum f. sp. ciceris isolates obtained by DAMD-PCR markers. 


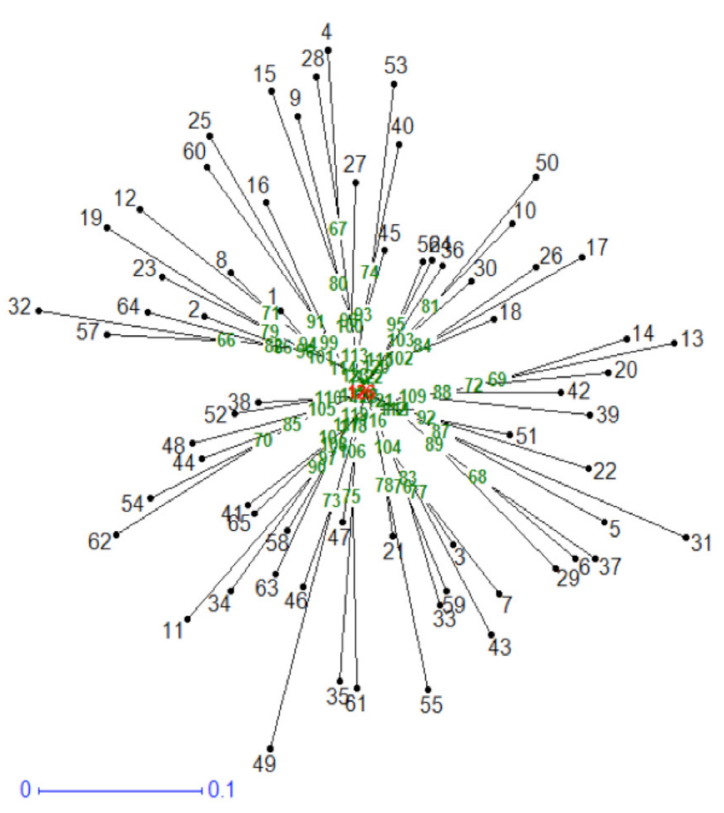

Fig. 3. Cluster analysis of 65 of Fusarium oxysporum f. sp. ciceris isolates obtained by combined data (ISSR + DAMD-PCR markers).

\section{Diversity and population structure of FOC isolates by combined data}

The general dendrogram (Fig. 3) that was constructed using the combined data of all molecular markers used in this study (ISSR and DAMD-PCR) grouped the FOC isolates into five major clusters. Cluster I comprised 12 FOC isolates, mostly from the Kermanshah province, except two isolates from Kordestan. Cluster II and II contained 8 and 9 FOC isolates, respectively, which most of them collected from the Kermanshah province. Cluster IV and $\mathrm{V}$ comprised 30 and 6 FOC isolates. All isolated FOC in cluster $\mathrm{V}$ originated from the Kermanshah province. The general dendrogram was generally consistent with the dendrograms generated by ISSR and DAMD-PCR markers. The cophenetic coefficient for different molecular marker types ( 0.76 for ISSR and 0.72 for DAMD-PCR) indicated good fit for clustering. The genetic structure of 65 FOC

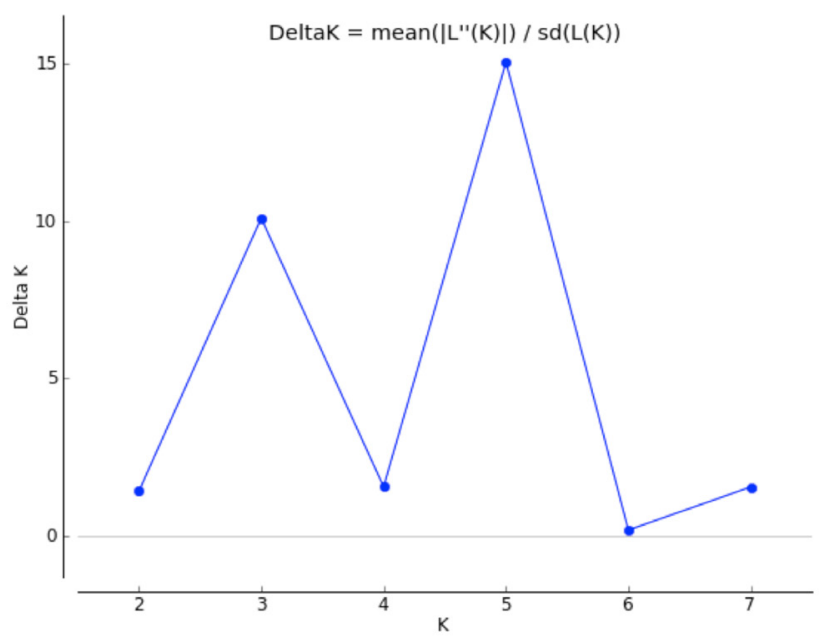

Fig. 4. Determination of the optimal value of $K$, based on three independent runs and $\mathrm{K}$ ranging from 1 to 10 based on 65 of Fusarium oxysporum $\mathrm{f}$. sp. ciceris isolates using ISSR + DAMDPCR markers.

isolates was further explored using the Bayesian clustering model implemented in the STRUCTURE software. The results showed the highest peak at $K=5$ indicating the presence of five major clusters (Fig. 4). These results mean that the collected FOC isolates should be divided into five populations (Fig. 5).

\section{Discussion}

The study of genetic diversity within in any pathogenic fungal species is critical for disease management and mainly attributed to important factors such as sexual habitat, gene flow and migration within populations and selection pressure (McDonald 1997; Aghamiri et al. 2015). Fusarium oxysporum f. sp. ciceris (FOC), a causal agent of chickpea wilt, is highly variable in morphology, virulence ability that consists of different races and pathotypes (Jendoubi et al. 2017). Thus, study of the natural genetic diversity pattern is very fundamental for disease management. The present study showed the genetic diversity level in 65 FOC isolates collected from west of Iran using two comparative
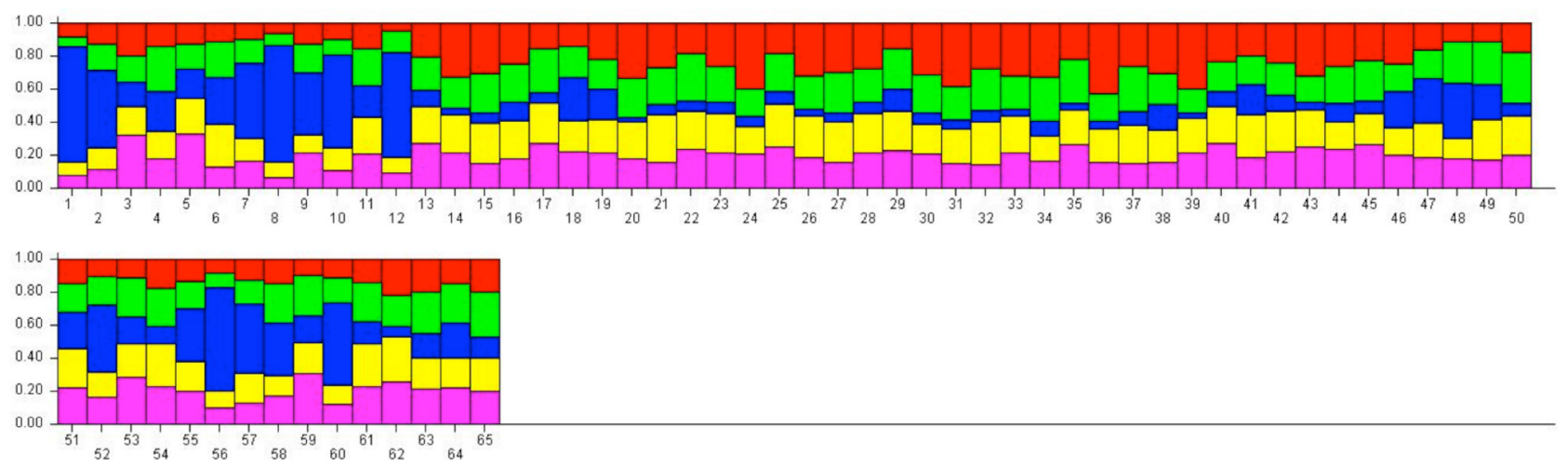

Fig. 5. Population structure of 65 of Fusarium oxysporum f. sp. ciceris isolates based on ISSR and DAMD-PCR markers. 
molecular markers techniques, ISSR and DAMD-PCR. In our study, two different types of markers showed high level of polymorphism and were found to be effective in determining genetic diversity in FOC isolates. Their efficiency was evident from the high number of polymorphic bands, PIC and the marker index. A high level of diversity in FOC isolates using SSR (Mohamed et al. 2015; Kashyap et al. 2016), RAPD (Sivaramakrishnan et al. 2002), ERIC and BOX (Kashyap et al. 2016) and AFLP (Sivaramakrishnan et al. 2002) markers had been reported earlier. In our study, two different markers showedthe relatively same efficiency with regard to average polymorphism and PIC value. Although both ISSRs and DAMD-PCR markers showed relatively similar grouping of FOC isolates, ISSR efficiency was evident from high number of polymorphic bands, PIC and the marker index. To our knowledge, the present study is the first analysis of the genetic diversity of FOC isolates using DAMD-PCR markers.

The results of the present study showed that FOC isolates from Iran varied in morphology, virulence and genetic structure. Cultural and morphological characteristics such as colony color, clamydospore position and diseases severity have been used to discriminate or characterize the isolates of FOC (Kashyap et al. 2016). FOC isolates showed different categories on the basis of colony color, clamydospore position and virulence severity. However, there was no strong correlation noticed between morphology, virulence and geographical origin of the isolates.

According to isolate virulence, FOC isolates were graded in four groups as avirulent ( $0 \%$ wilt), less virulent (1 $-20 \%$ wilt), moderately virulent ( $21-50 \%$ wilt) and highly virulent (>51\% wilt). The results showed that about $20 \%$ of isolates were highly virulent (>50\% wilt damage) and the remaining isolates were moderately or less virulent. Cluster analysis using ISSR and DAMD-PCR markers grouped the FOC isolates in five distinct clusters. The results obtained from the STRUCTURE analysis are in good agreement with those obtained from Un-weighted pair-group (UPGMA) clustering generated by ISSR and DAMD-PCR markers. It is also clear from the results that both molecular markers revealed highly genetic variation between FOC isolates from different geographical regions.

A high rate of genetic diversity occurred in FOC isolates, which might be mediated by gene mutation, chromosomal segment loss and transposable elements or recombination processes in fungal genome (Mehrabi et al. 20111; Soren et al. 2016). Kashyap et al (2016) showed that the genetic similarity among the Indian FOC isolates was not correlated with virulence, race compositions or geographic origin of the isolates. These finding are in agreements with previous studies FOC isolates from India and Sudan (Soren et al. 2016; Mohamed et al. 2015). the pathogenicity test for race identification of FOC isolates was not used in this study. Therefore, complementary pathogenicity studies and specific molecular markers analysis for characterization of FOC races are very useful and may be helpful to reveal correlation between FOC virulence and geographical origin (Mohamed et al. 2015).

The high genetic variability observed between FOC isolates is very important to pathogens to adapt to environmental changes such as overcoming a new resistance gene in a crop or sensitivity towards crop protection agents (Mehrabi et al. 2011). Molecular diagnostic tools and the availability of many new whole genome sequences of fungi will enable to answer this question. The results form cluster analysis generated by ISSR and DAMD-PCR markers indicated that the genetic similarity among the Iranian FOC isolates could be partly explained by geographic origin. It can be inferred from our results that chickpea FOC isolates have a heterothallic origin. Previous studies on genetic diversity in FOC are in agreement with the hypothesis that Fusarium spp. fungi exhibit a sporadic and cryptic sexual cycle (Dubey et al. 2010) and it also suggested that all fungi with no known sexual stage are originally heterothallic, and most of them should display a sexual reproduction (Turgeon 1998; Taylor et al. 1999; Kashyap et al. 2016). In conclusion, the genetic variation identified in this study can provide useful information for disease management and identification of effective resistance sources to FOC in chickpea wilt resistance breeding programs.

\section{References}

Aghamiri A., Mehrabi R., Talebi R. 2015. Genetic diversity of Pyrenophera tritici-repentis isolates, the causal agent of wheat tan spot disease from Northern Iran. Iranian J. Biotechnol. 13: 39-44.

Bakhsh A, Iqbal S.M., Haq I.K. 2007. Evaluation of chickpea germplasm for wilt resistance. Pak. J. Bot. 39: 583-593.

Cachinero J.M., Hervás A., Jiménez-Díaz R.M., Tena M. 2002. Plant defence reactions against fusarium wilt in chickpea induced by incompatible race 0 of Fusarium oxysporum $\mathrm{f}$. sp.ciceris and nonhost isolates of F. oxysporum. Plant Pathol. 51: 765-776.

Chand H., Khirbat S.K. 2009. Chickpea wilt and its management - a review. Agric. Rev. 30: 1-12.

Dubey S.C., Tripathi A., Singh S.R. 2010. ITS-RFLP fingerprinting and molecular marker for detection of Fusarium oxysporum $\mathrm{f}$. sp. ciceris. Folia Microbiol. 55: 629-634.

Hajibarat Z., Saidi A., Hajibarat Z., Talebi R. 2015. Characterization of geneticdiversity in chickpea using SSR markers, Start Codon Targeted Polymorphism (SCoT) and Conserved DNA-Derived Polymorphism (CDDP). Physiol. Mol. Biol. Plants 21: 365-373.

Haware M.P., Nene Y.L., Rajeshwari R. 1978. Eradication of Fusarium oxysporum f. sp. ciceri transmitted in chickpea seed. Phytopathology 68: 1364-1367.

Jalali B.L., Chand H. 1992. Plant Diseases of International Importance: Diseases of Cereals and Pulses. Vol 1. Prentice Hall, Englewood Cliffs.

Jannatabadi A.A., Talebi R., Armin M., Jamalabadi J., Baghebani N. 2014. Genetic diversity of Iranian landrace chickpea (Cicer arietinum $\mathrm{L}$.) accessions from different geographical origins as 
revealed by morphological and sequence tagged microsatellite markers. J. Plant. Biochem. Biotechnol. 23: 225-229.

Jendoubi W., Bouhadida M., Boukteb A., Béji M., Kharrat M. 2017. Fusarium wilt affecting chickpea crop. Agriculture 7: 23.

Jiménez-Díaz R.M., Castillo P., del Mar Jiménez-Gasco M., Landa B.B., Navas-Cortés J.A. 2015. Fusarium wilt of chickpeas: Biology, ecology and management. Crop. Protect. 73: 16-27.

Jiménez-Fernández D., Landa B.B., Kang S., Jiménez-Díaz R.M., Navas-Cortés J.A. 2013. Quantitative and microscopic assessment of compatible and incompatible interactions between chickpea cultivars and Fusarium oxysporum f. sp. ciceris races. PLoS One 8: e61360.

Jiménez-Gasco M.D.M., Jiménez-Díaz R.M. 2003. Development of a specific polymerase chain reaction-based assay for the identification of Fusarium oxysporum f. sp. ciceris and its pathogenic races 0, 1A, 5, and 6. Phytopathology 93: 200-209

Jiménez-Gasco M.M., Navas-Cortés J.A., Jiménez-Díaz R.M. 2004. The Fusarium oxysporum f. sp. ciceris/Cicer arietinum pathosystem: A case study of the evolution of plant-pathogenic fungi into races and pathotypes. Int. Microbiol. 7: 95-104.

Kang H.W., Park D.S., Go S.J., Eun M.Y. 2002. Fingerprinting of diverse genomes using PCR with universal rice primers generated from repetitive sequence of Korean weedy rice. Mol. Cells 13: 281-287

Kashyap P.L., Rai S., Kumar S., Srivastava A.K. 2016. Genetic diversity, mating types and phylogenetic analysis of Indian races of Fusarium oxysporum f. sp. ciceris from chickpea. Arch. Phytopathol. Plant Protect. 49: 533-553.

Kumar S., Singh R., Kashyap P.L., Srivastava A.K. 2013. Rapid detection and quantification of Alternaria solani in tomato. Sci. Hortic. 151: 184-189.

McDonald BA. 1977. The population genetics of fungi: Tools and technique. Phytopathology 87:448-453.

Mehrabi R., Bahkali A.H., Abd-Elsalam K.A., Moslem M., Ben M'Barek S., Gohari A.M., Karimi Jashni M., Stergiopoulos I., Kema G.H.J., de Wit P.J.G.M. 2011. Horizontal gene and chromosome transfer in plant pathogenic fungi affecting host range. FEMS Microbiol. Rev. 35: 542-554

Mohamed O.E., Hamwieh A., Ahmed S., Ahmed N.E. 2015. Genetic variability of Fusarium oxysporum f. sp. ciceris population affecting chickpea in the Sudan. J. Phytopathol. 163: 941-946.

Mohammadi K.H, Talebi R. 2015. Interrelationships and genetic analysis of seed yield and morphological traits in mini core collection of Iranian landrace, breeding lines and improved chickpea (Cicer arietinum L.) cultivars. Genetika 47: 383-393.
Muiru W.M., Koopmann B., Tiedemann A.V., Mutitu E.W., Kimenju J.W. 2010. Use of repetitive extragenic palindromic (REP), enterobacterial repetitive intergenic consensus (ERIC) and BOX sequences to fingerprint Exserohilum turcicum isolates. J. Appl. Biosci. 30: 1828-1838.

Pande S., Rao J.N., Sharma M.2007. Establishment of the chickpea wilt pathogen Fusarium oxysporum f. sp. ciceris in the soil through seed transmission. Plant Pathol. J. 23: 3-6.

Patil P.D., Mehetre S.S., Mandare V.K., Dake G.N. 2005. Pathogenic variation among Fusarium isolates associated with wilt of chick-pea (Cicer arietinum L.). Ann. Plant Protect. Sci. 13: 427-430.

Perrier X., Flori A., Bonnot F. 2003. Data analysis methods. In: Hamon P., Seguin M., Perrier X., Glaszmann J.C. (eds) Genetic Diversity of Cultivated Tropical Plants. Science Publishers, Enfield, pp. 43-76.

Perrier X., Jacquemoud-Collet J.P. 2006. DARwin software. http:// darwin.cirad.fr/darwin

Pritchard J.K., Stephens M., Donnelly P. 2000. Inference of population structure using multilocus genotype data. Genetics 155: 945-959.

Sharma K.D., Muehlbauer F.J. 2007. Fusarium wilt of chickpea: physiological specialization, genetics of resistance and resistance gene tagging. Euphytica 157: 1-14.

Sharma M., Varshney R.K., Rao J.N., Kannan S., Hoisington D., Pande S. 2009. Genetic diversity in Indian isolates of Fusarium oxysporum f. sp. ciceris, chickpea wilt pathogen. Afr. J. Biotechnol. 8: 1016-1023.

Sivaramakrishnan S., Seetha K., Singh S.D. 2002. Genetic variability of Fusarium wilt pathogen isolates of chickpea assessed by molecular markers. Mycopathology 155: 171-178.

Soren K.R., Gangwar P., Chaudhary R.G., Datta S. 2016. Population distribution and genetic relatedness in Indian Fusarium udum isolates based on ribosomal internal transcribe spacer and elongation factor. J. Environ. Biol. 36: 1063-1070.

Talebi R., Mardi M., Jelodar N.A.B., Razavi M., Pirseyedi S.M., Kema G., Mehrabi R., Ebrahimi M., Marcel T. 2010. Specific resistance genes in wheat Chinese landrace 'Wangshuibai' against two Iranian Mycosphaerella graminicola isolates. Int. J. Biol. 2: 181-188.

Taylor J.W., Geiser D.M., Burt A., Koufopanau V. 1999. The evolutionary biology and population genetics underlying fungal strain typing. Clin. Microbiol. Rev. 12: 126-146.

Turgeon B.G. 1998. Application of mating type gene technology to problems in fungal biology. Annu. Rev. Phytopathol. 36: 115-137. 